\title{
LA CALLE Y EL COMERCIO: TRANSFORMACIONES DEL JIRÓN CUSCO (LIMA) Y DE LA CALLE EL SOL (CUSCO) - PERÚ
}

\author{
THE STREET AND COMMERCE: TRANSFORMATION OF JIRÓN CUSCO (LIMA) AND THE ROAD EL SOL (CUSCO) - PERU
}

\author{
A RUA E O COMÉRCIO: TRANSFORMAÇÕES DO JIRÓN CUSCO (LIMA) E DA RUA EL SOL (CUSCO) - PERU
}

\section{RESUMO}

Introducción: Estudiamos dos calles, Jirón Cuzco (ciudad de Lima, Perú) y El Sol (ciudad de Cuzco, Perú). Objetivo: Nuestro objetivo fue analizar las transformaciones espacio-temporales, especialmente en el uso. Hicimos lectura bibliográfica, de fuentes documentales, trabajo de campo (reconocimiento y fotografías) y elaboramos mapas. Resultados: Jirón Cuzco fue una calle residencial y comercial, ocupada por migrantes chinos en el siglo XIX e integró el área pericentral del centro histórico de Lima en el siglo XX, con comercio intenso, varias edificaciones degradadas y ocurrieron conflictos diversos por su apropiación. Hoy, predomina uso comercial, especialmente el informal. El Sol fue una vía, en el siglo $\mathrm{XIX}$, que poseía un río en su tramo, con casas de uso residencial, pasando a ser una arteria moderna en el inicio del siglo XX. Actualmente es la principal vía del centro histórico de Cuzco, con uso financiero, comercial y turístico. Conclusión: El carácter diverso de estas calles se manifiesta en usos diferenciados, sea como lugares de pasaje, de uso residencial, comercial, de visita turística, de reuniones, encuentros y trabajo.

Palabras-clave: Calle. Comercio. Jirón Cusco. Calle El Sol. Centro Histórico.

\begin{abstract}
Introduction: We have studied two roads, the Jirón Cusco (City of Lima, Peru) and the El Sol, (city of Cuzco, Peru). Our aim was to analyse the space-time transformations, particularly in use. Objective: We have conducted a bibliographic review of documental sources, fieldwork (recognizing and photographic survey) and elaboration of maps. Results: Jirón Cusco was a residential and commercial road, occupied by Chinese in the XIX century, and integrated the pericentral part of the historic centre of Lima in the XX century, with intense commerce, where several edifications were degraded and conflicts arose aimed at its appropriation. Nowadays, the commercial use is predominant, particularly the informal commerce. El Sol was a road that had a river in its way in the XIX century, with houses of residential use. In the beginning of XX century, it was transformed in a modern main road. Currently, it is the main road of the Cuzco historic centre, with financial, commercial and touristic use. Conclusion: The diverse feature of these roads is represented by their different use, which range from crossing places to residential, commercial, touristic, meeting and working places.
\end{abstract}

Keywords: Road. Commerce. Jirón Cusco. Road El Sol. Historic Center.

\section{RESUMO}

Introdução: Estudamos duas ruas, a Jirón Cusco (na cidade de Lima, Peru) e a El Sol, (cidade de Cuzco, Peru). Objetivo: Nosso objetivo foi analisar as transformações espaço-temporais, especialmente no uso. Fizemos leitura bibliográfica, de fontes documentais, trabalho de campo (reconhecimento e levantamento fotográfico) e elaboração de mapas. Resultados: Jirón Cusco foi uma rua residencial e comercial, ocupada pelos migrantes chineses no século XIX e integrou a parte pericentral do centro histórico de Lima no século $\mathrm{XX}$, com comércio intenso, várias edificações foram degradadas e gestaram-se conflitos de diversos por sua apropriação. Hoje, predomina o uso comercial, especialmente o informal. El Sol foi uma via, no século $\mathrm{XIX}$, que possuía um rio em seu transcurso, com casas de uso residencial, passando a ser uma artéria moderna no início do século XX. Atualmente é a principal via do centro histórico de Cuzco, com uso financeiro, comercial e turístico. Conclusão: $O$ caráter diverso destas ruas manifesta-se nos usos diferenciados, ora sendo lugares

\section{Rita de Cássia Gregório de} Andrade ${ }^{\text {a }}$

(D) Tania Herrera Romero ${ }^{b}$

${ }^{a}$ Universidade Estadual Paulista (UNESP), Presidente Prudente, São Paulo, Brasil

${ }^{\text {b }}$ Universidad Nacional Mayor de San Marcos (UNMSM), Lima, Peru

DOI: 10.12957/geouerj.2021.44430

Correpondência:

ritagandrade@hotmail.com

Recebido em: 20 fev. 2019 Aceito em: 22 ago.2019 
La calle y el comercio: transformaciones del jirón cusco (Lima) y de la calle el sol (Cusco) - Perú Andrade

de passagem, ora residencial, comercial, de visita turística, reuniões, encontros e trabalho.

Palavras-chave: Rua. Comércio. Jirón Cusco. Rua El Sol. Centro Histórico. 


\section{INTRODUCCIÓN}

En este artículo exploramos las transformaciones de dos calles peruanas. Una de ellas es el Jirón Cusco, en la ciudad de Lima, y la otra es la Avenida El Sol, ubicada en la ciudad de Cusco. Ambas calles se encuentran en los centros históricos de Lima y Cusco - áreas urbanas que dieron origen a estas ciudades.

La calle puede ser vista desde diferentes enfoques. Como forma urbana fundamental de la ciudad, es una realidad física delimitable que dinamiza la vida urbana (DELGADO, 1999; CAPEL, 2002). Se trata de un eje híbrido (público y privado) articulador y organizador del comercio y de los servicios. La calle es un puente entre la edificación y la ciudad, es una de las manifestaciones de la evolución histórica urbana.

Algunas calles pertenecientes a ciudades latinoamericanas, como aquellas que existen desde períodos precolombino y colonial, están ubicadas en centros históricos. Por lo tanto, son calles comerciales y turísticas, con importante patrimonio arquitectónico, sea conservado o degradado, a depender de la presencia o ausencia de políticas de protección y acciones de rehabilitación.

La calle es lo que Capel (2003) denomina la urbs, el espacio físico de la ciudad, que estructura la forma urbana. A menudo, es configurada por el mercado de vivienda y por agentes económicos involucrados con el comercio. Además de espacio de circulación (como pensaron los urbanistas del funcionalismo del siglo XX), cada vez más dominada por el auto, la calle es (o debería ser) locus de diversidad, encuentros, sociabilidad e intercambios materiales (mercancías, capitales, personas) e inmateriales (informaciones, ideas etc.). Se trata, a la vez, de un lugar de paso y de permanencia.

En la sociedad capitalista, encierra dentro de sí las desigualdades existentes entre los habitantes urbanos y en ella se desarrollan conflictos diversos. Es locus de la pugna constante por la apropiación o dominación de los ciudadanos sobre otros, espacio mercantilizado y espacio de sobrevivencia. En línea con Jordi Borja (2012), se puede decir que la calle, en tanto que espacio público, expresa la democracia en su dimensión territorial: es donde las sociedades manifiestan sus demandas, sus necesidades, donde se gesta una memoria colectiva.

La importancia de recorrer las calles estriba en que, mediante ellas, conocemos la ciudad. Como dice Lefebvre (1999), la ciudad se inscribe en sus muros y en sus calles. Es así que la calle permite explorar la ciudad y sus transformaciones, cuya escala espacial permite profundizar en detalles particulares.

Por ejemplo, verificamos en Brasil que el análisis de una calle es poco común en las investigaciones del campo de la Geografía, aunque se destaque, a mediados del siglo XX, investigadores como Tricart (1951). Aunque no sea una escala de análisis frecuente, hay investigadores de las últimas décadas interesados en el asunto, como Bresciani (1992), Meyer (1992) y Maia (2008). Asimismo, la calle es una unidad de estudio del 
espacio urbano que no suele ser trabajada por los geógrafos o investigadores urbanos en Perú, quienes privilegian el nivel distrital o la ciudad en su conjunto. En ambos casos, por lo general, toman como referencia la demarcación estatal.

Las dos calles que analizamos, aunque físicamente delimitables, resultan de factores multiescalares. Por un lado, se trata de condicionantes nacionales y regionales, expresados en la regulación pública y en las desigualdades sociales, pero también se trata de fuertes impactos de la urbanización del mundo capitalista y occidental, como la inmigración extranjera, el turismo etc. Este artículo es un escrito descriptivo y exploratorio que presenta los cambios ocurridos en dos calles, ambas ubicadas en el centro más antiguo de una ciudad grande y metropolitana - Lima - y una ciudad intermedia de la sierra andina - Cusco.

Es pertinente comprender la calle como locus de transformación urbana a lo largo del tiempo, de riqueza de elementos sociales y económicos representativos de la ciudad. En este sentido, nuestro objetivo es explorar las transformaciones de dos calles peruanas, como también su actual uso, que se destaca en lo comercial. Para ello, consultamos materiales académicos (libros y artículos científicos) y fuentes periodísticas y documentales. Asimismo, realizamos trabajo de campo en cada una de las calles. El trabajo de campo incluyó exploración a pie y observaciones. Además del registro fotográfico, elaboramos mapas que complementan el análisis.

Elegimos la calle/avenida El Sol, pues, es una de las principales vías de la ciudad de Cusco. Ella fortalece la centralidad del centro histórico por su intensa vida comercial, financiera y turística. Por su lado, el Jirón Cusco, en Lima, se ubica en un área de intensa actividad comercial. Se trata de una calle importante para el comercio mayorista y un polo de atracción reconocido a nivel metropolitano y nacional. No tenemos la finalidad de realizar un estudio comparativo, entre dos calles que son distintas en varios aspectos. Esperamos producir información y conocimiento que contribuyan a los estudios sobre la calle y que sirvan de inspiración para proposiciones sobre la planificación de esos espacios.

En fin ¿para qué explorar las transformaciones de dos calles, desde la Geografía? 1) para tener el registro del espacio urbano pretérito y de los usos y apropiaciones a lo largo del tempo. Dicho de otra manera, para comprender la evolución de las formas espaciales, en relación con el tempo; 2) Producir conocimiento que sirva de base para futuras proposiciones urbanísticas, para la planificación de calles que cumplan el rol de sociabilidad y que, por su antigüedad, riqueza arquitectónica y patrimônio, puedan conservar rasgos de la historia urbana.

\section{JIRÓN CUSCO - CIUDAD DE LIMA}

La calle elegida en Lima es un segmento del Jirón Cusco, ubicado en el centro histórico, fuera del área más monumental. Esta vía es un largo eje de aproximadamente 2.89 kilómetros, que remite al transeúnte a 
diversos tiempos de la ciudad. Así, atraviesa el tramo donde está la edificación en la cual funcionó el bohemio café-cine-bar Palais Concert ${ }^{1}$, en el cruce de Jirón de la Unión con la Avenida Emancipación. La transformación del sistema de transporte urbano colectivo de la ciudad se observa también en esta vía, pues parte del eje del moderno Metropolitano ${ }^{2}$ se extiende desde la Plaza Unión hasta el Jirón Lampa, en cuya esquina se ubica el antiguo edificio del Banco Wiese, inaugurado en diciembre de 1963 y hoy convertido en un supermercado (CÓRDOVA, 2013).

El tramo elegido posee hoy intenso uso comercial del suelo (figura 1). La actividad comercial que predomina en Jirón Cusco, entre la Avenida Abancay y el Jirón Huanta, es comercio mayorista ${ }^{3}$ de productos de plástico importados de China.

Figura 1. Dinámica cotidiana/Jirón Cusco - 2019, Cruce de Jirón Cusco con Jirón Andahuaylas. Fuente: Trabajo de campo, junio 2019. Fotografía: Tania Herrera.

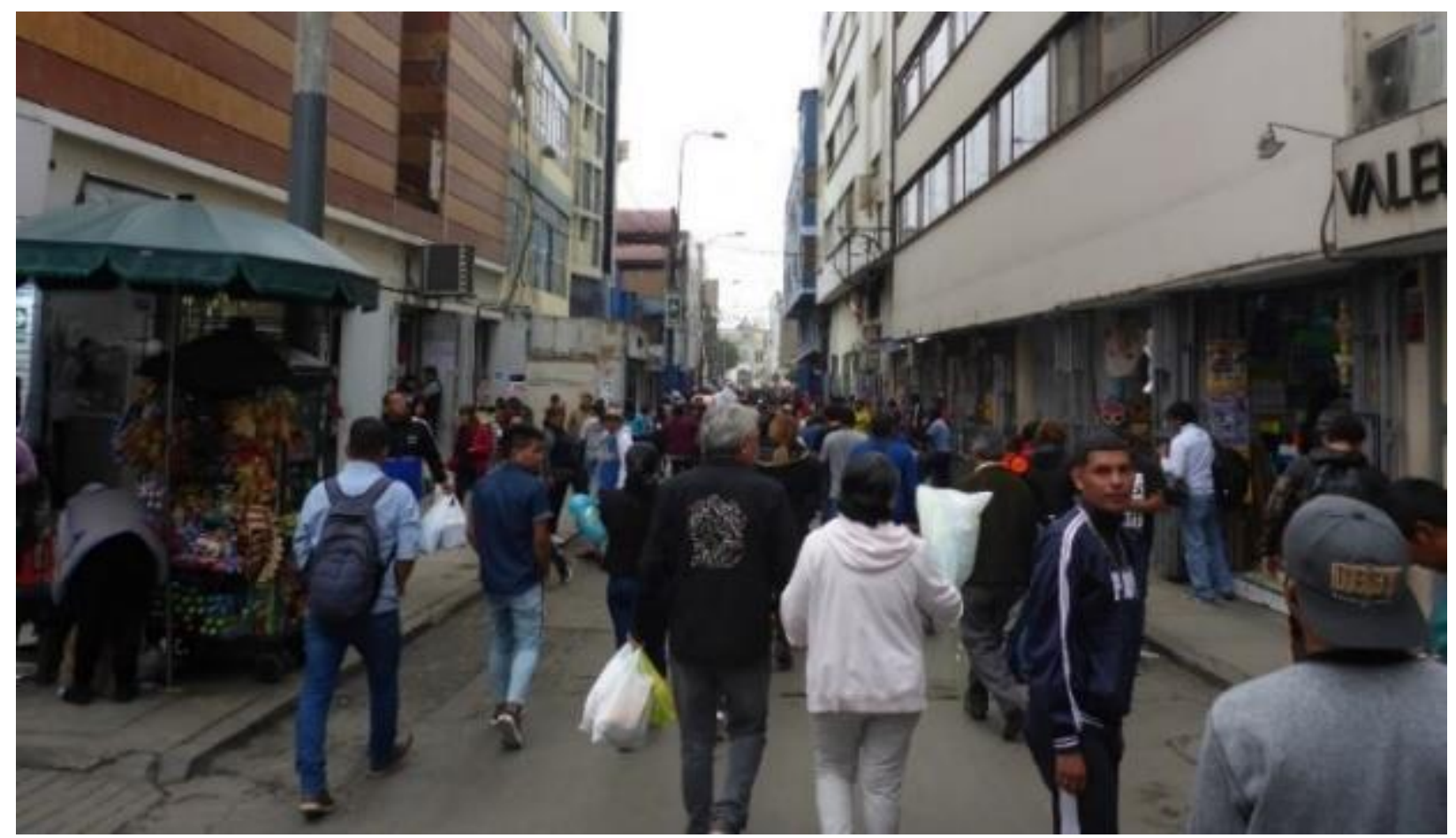

\footnotetext{
${ }^{1}$ En esta edificación se encontraban renombrados intelectuales y escritores peruanos a inicio del siglo XX - Pedro Abraham Valdelomar Pinto, Alfredo González Prada, Félix del Valle, José Carlos Mariátegui, entre otros. Hoy contiene uso totalmente distinto, estando ocupada por la tienda de ropa de la multinacional chilena Ripley.

2 El Metropolitano funciona junto al transporte colectivo más precarizado, con combis y buses antiguos.

${ }^{3}$ El comercio mayorista consiste en importar grandes cantidades de mercancía para luego ofrecerla a bajo precio, ya que el costo disminuye según la cantidad de artículos que se compra. Los compradores son comerciantes menores o intermedios, quienes generalmente poseen locales de venta de artículos diversos por unidades. Por ejemplo, el costo al por mayor de 100 pelotas de plástico equivale a S/. 0.57 la unidad, mientras que su precio de venta al por menor se estima en S/. 3.00 la unidad.
} 
Las mercancías vendidas son juguetes, útiles escolares, adornos para el hogar, productos de tocador (ganchos y elásticos para el cabello), material para decorar fiestas infantiles y otra gran variedad de artículos. La actividad comercial domina el espacio público y privado según las festividades más importantes para los peruanos: día de la madre, día del padre, fiestas patrias, navidad o año nuevo. La identidad propia de esta calle se extiende por vías paralelas y perpendiculares, en lo que se conoce popularmente como Mesa Redonda (ver figura 2).

Figura 2. Ubicación del Jirón Cusco - 2019, Superposición de áreas sobre el Jirón Cusco. Elaborado por Tania Herrera, junio 2019. Fuente: MML, 2019; Shimabukuro, 2015; Google Earth, 2019; INEI, 2007.
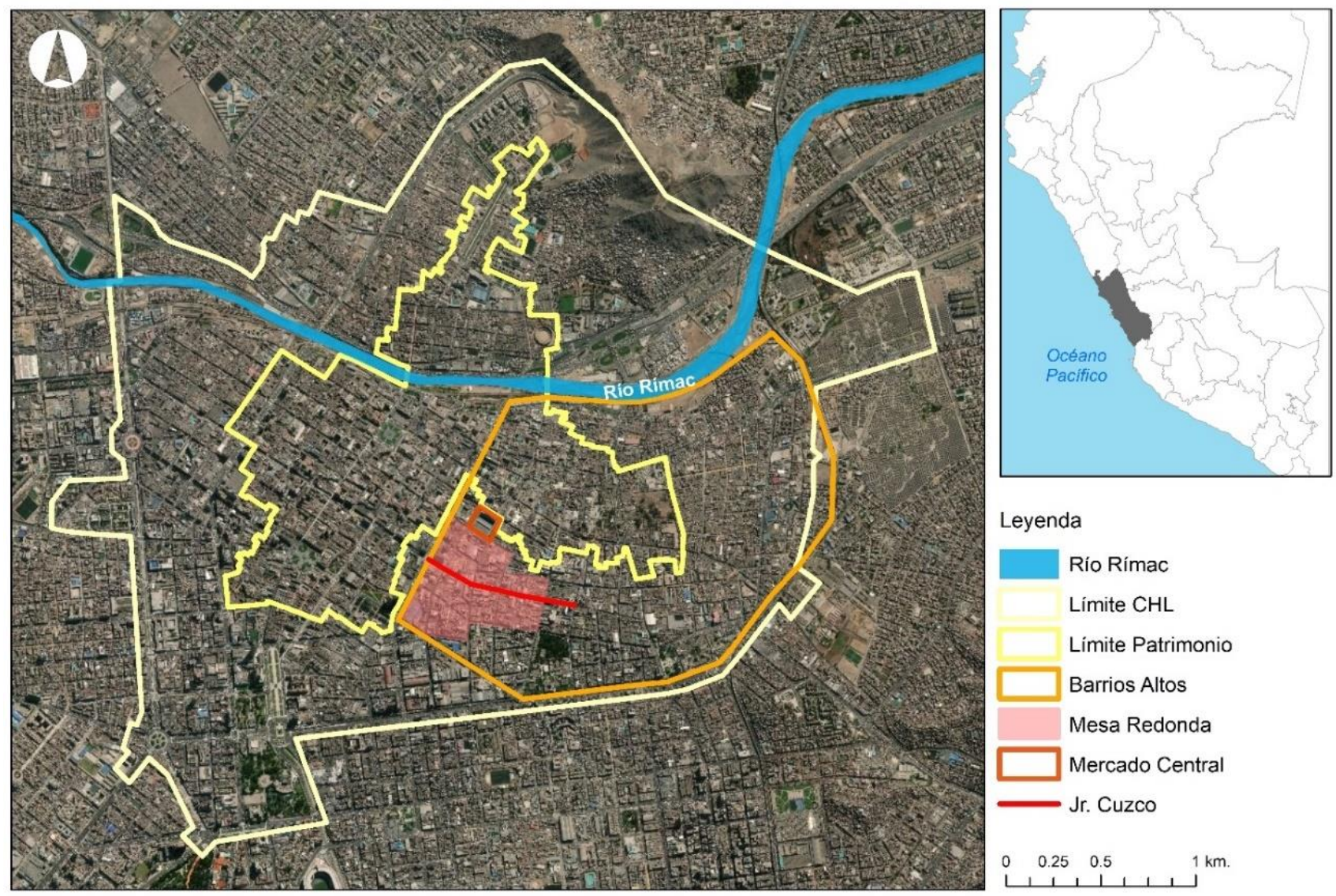

El tramo elegido de Jirón Cusco es la columna vertebral de Mesa Redonda, como pudimos ver en la figura 2. Su característica de espacio del comercio mayorista de productos chinos es reconocida a escala nacional. Podemos apreciar, en la figura 3, que es una vía influenciada por espacios importantes del centro, como el Barrio Chino y el Mercado Central, con función de abasto. 
Figura 3. Vía del Jirón Cusco de más intensa concentración comercial - 2019, Tramo elegido de Jirón Cusco, entre la Avenida Abancay y el Jirón Cangallo. Elaborado por Tania Herrera, junio 2019. Fuente: MML, 2019; Google Earth, 2019.

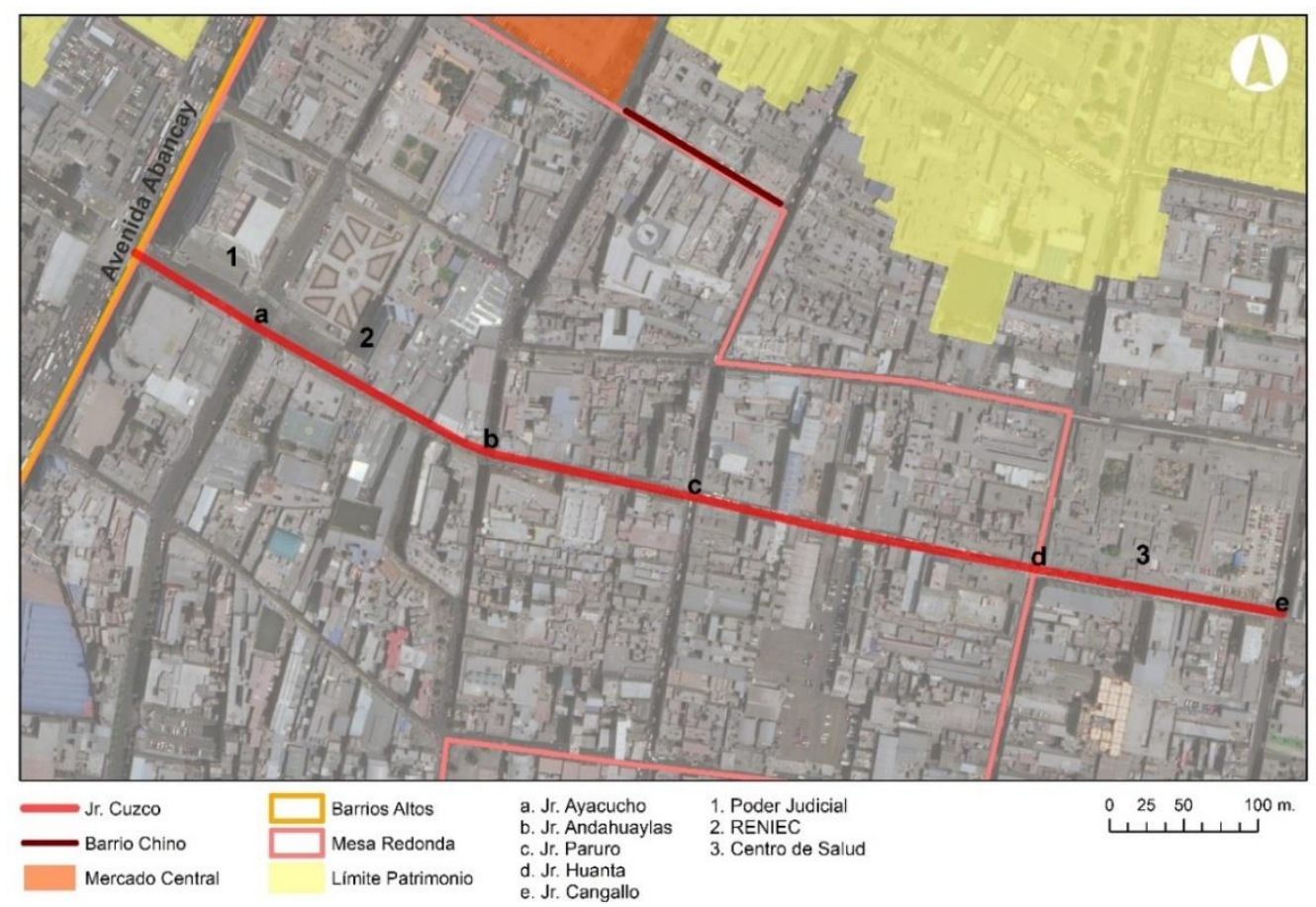

Para entender la configuración de Mesa Redonda, estructurada por el Jirón Cusco, hay que retroceder a mediados del siglo XIX y rastrear en la migración china al Perú4. La progresiva fuerza que tomó la comunidad de migrantes en el Perú hizo que los peones chinos de las haciendas dejen su condición de infra-clase dedicada a la agricultura y pasen a trabajar en actividades comerciales en contextos urbanos. Para los que laboraban en la zona rural, cuando terminaba su contrato con la hacienda, algunos abrían un pequeño negocio (YAMAWAKI, 2002).

Hacia 1869 se registra migrantes chinos en Lima, laborando en comercios diversos, principalmente en las populares fondas, que fueron pequeños puestos de comida, donde generalmente atendían personas negras y mujeres indígenas - aunque haya sido concurridas, incluso, por la élite. Las fondas estaban destinadas principalmente a las clases populares, quienes comían de pie alrededor de los puestos (op.cit.). Continuaron a esta pequeña escala hasta fines del siglo XIX (HU, 1987).

A partir de 1904 se identifica un nuevo ciclo de inmigración china. Estos nuevos migrantes tenían el control del abastecimiento de pequeñas tiendas de abarrotes. Para 1919, se observa nuevamente un incremento de negocios

\footnotetext{
${ }^{4}$ Los trabajadores que llegaron en esta época se diferenciaban en dos clases sociales. Por un lado, estaban los culíes, inmigrantes chinos que llegaron entre 1850 y 1874, sin capital y, generalmente, para laborar en condiciones de semi-esclavitud en las haciendas costeras, en el cultivo de algodón y caña de azúcar (Rodríguez, 1987). Por otro lado, estaban los comerciantes chinos que llegaban con capital para invertir en negocios diversos, como el comercio en la ciudad. Al parecer, las fronteras entre estas dos clases se tornarían más borrosas hacia fines del siglo XIX, cuando los vínculos entre ambos grupos se refuerzan debido a la intensidad del comercio y la extensión de las redes de migrantes (MC KEOWN, 2001).
} 
chinos. La mayoría de estas compañías vendía abarrotes y mercancías diversas, productos importados de China y Japón, aunque también llevaban productos peruanos a comercializar a otros países (HU, 1987) 5 .

La intensidad del comercio en las calles del centro histórico de Lima contemporánea estaría vinculada a las olas migratorias desde 1940 y la búsqueda de empleo de los sectores populares, quienes poco a poco convirtieron las calles en un gran mercado (Fernández-Maldonado, 2015). En el centro de Lima, se observa que entre 1981 y 2017 la población residente disminuyó en más de 30\% (DAMMERT, 2018). Con las medidas de protección del área monumental ${ }^{6}$, el comercio más informal se desplazó cada vez más para áreas periféricas del centro histórico, como Mesa Redonda y cercanías del Mercado Central de Lima.

Actualmente, tanto el Mercado Central como el Barrio Chino irradian su influencia en el Jirón Cuzco y el área de Mesa Redonda. El alcance comercial del Jirón Cuzco y su cercanía no es solamente limeño, pues muchos comerciantes, pequeños, medianos o grandes, vienen desde diversas partes del país a proveerse de productos que compran a precio accesible. Ese espacio constituye, desde inicio del siglo XX, el emporio de venta de productos chinos en la ciudad capital.

En el Jirón Cusco también se encuentran vendedores ambulantes de alimentos y estibadores, quienes transportan pesadas cajas desde los almacenes hasta las tiendas, y desde las tiendas hasta los vehículos de los compradores, como se aprecia en la figura 4.

Figura 4. Dinámica comercial y poblacional del Jirón Cusco - 2013, Estibador cargando cajas en el cruce de Jirón Cusco con Jirón Paruro. Fuente: Google Street View, abril, 2013.

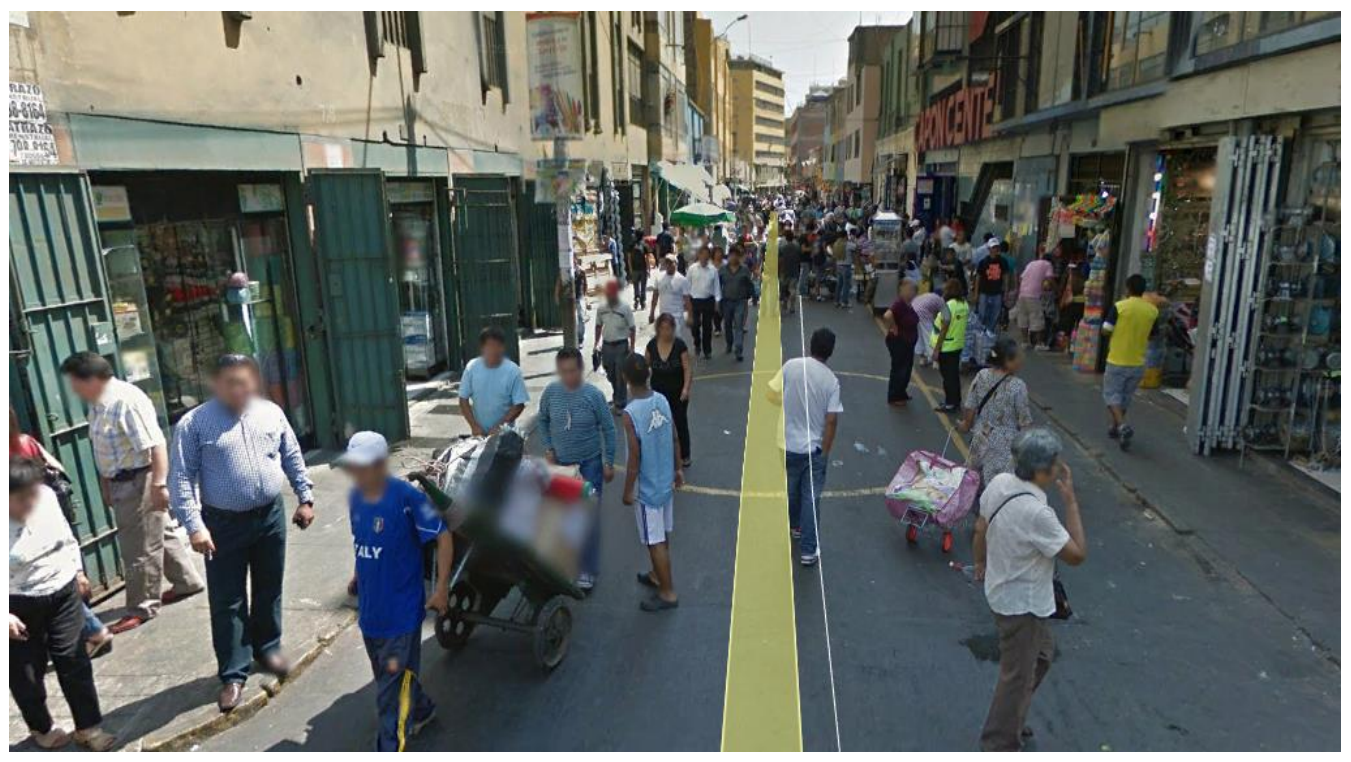

\footnotetext{
${ }^{5}$ Cabe señalar que los inmigrantes chinos no eran los únicos comerciantes. Compartían las calles del centro de Lima con comerciantes peruanos, europeos y norteamericanos, por lo que no es posible afirmar su total hegemonía espacial (op.cit.). La influencia de los chinos, como percibimos hasta los días actuales, ocurrió principalmente en la formación del Barrio Chino, ubicado cerca del Jirón Cusco, y al Mercado Central de abastos de Lima.

${ }^{6}$ El Centro Histórico de Lima fue declarado Património Cultural de la Humanidad, por la UNESCO, en 1991.
} 
Jirón Cusco y Mesa Redonda no cruzan el área considerada como patrimonio protegido del centro histórico, o sea, quedan fuera de esta centralidad política, comercial de servicio y turística. Jirón Cusco y Mesa Redonda están más integrados al Mercado Central de abastos, es decir, el área popular tomada por excesiva actividad comercial, principalmente informal, conforme hemos mencionado en párrafos anteriores.

Po lo tanto, las políticas de patrimonialización no cubren a Mesa Redonda ni al área de influencia del Barrio Chino. La poca atención de la gestión pública a estos espacios explica el trágico incendio ocurrido en la noche del 29 de diciembre de 2001, que enlutó al país con un total de 279 personas fallecidas (CHICOMA, 2017). El incendio se inició en el cruce de Jirón Cusco con Jirón Andahuaylas, desde donde el fuego se expandió rápidamente. La razón fue la explosión en cadena de productos pirotécnicos, iniciada a partir de la demostración de un vendedor ambulante. El fuego se expandió debido a la cantidad de mercadería almacenada en la calle y en las tiendas. Según testimonio de una de las sobrevivientes, antes del incendio había muy poca presencia policial o resguardo de la seguridad pública (RAMíREZ-CORZO, 2017).

Jirón Cusco y su entorno son áreas en rápida transformación urbanística, tanto de los edificios como de los usos vinculados al comercio. Esto se observa en la remodelación de antiguas casonas, así como en su demolición para el aprovechamiento del suelo en la construcción de edificios destinados a nuevas galerías o almacenes. Interesa notar que esta tendencia se expande más allá del área de estudio, en dirección al este.

Manuel Dammert (2018) habla de una disputa por el suelo y el aumento del valor de los inmuebles, por su atractivo para el uso comercial. En la figura 5 se observa nuevas edificaciones en Jirón Cusco destinadas para la actividad comercial. Se trata de predios más altos y con mayor capacidad de uso, lo que cambia la apariencia de esta calle.

Figura 5. Edificaciones del Jirón Cusco - 2019, Recientes edificios en Jirón Cusco, probablemente usados como almacén de mercadería. Fuente: trabajo de campo, junio 2019. Fotografía: Tania Herrera.
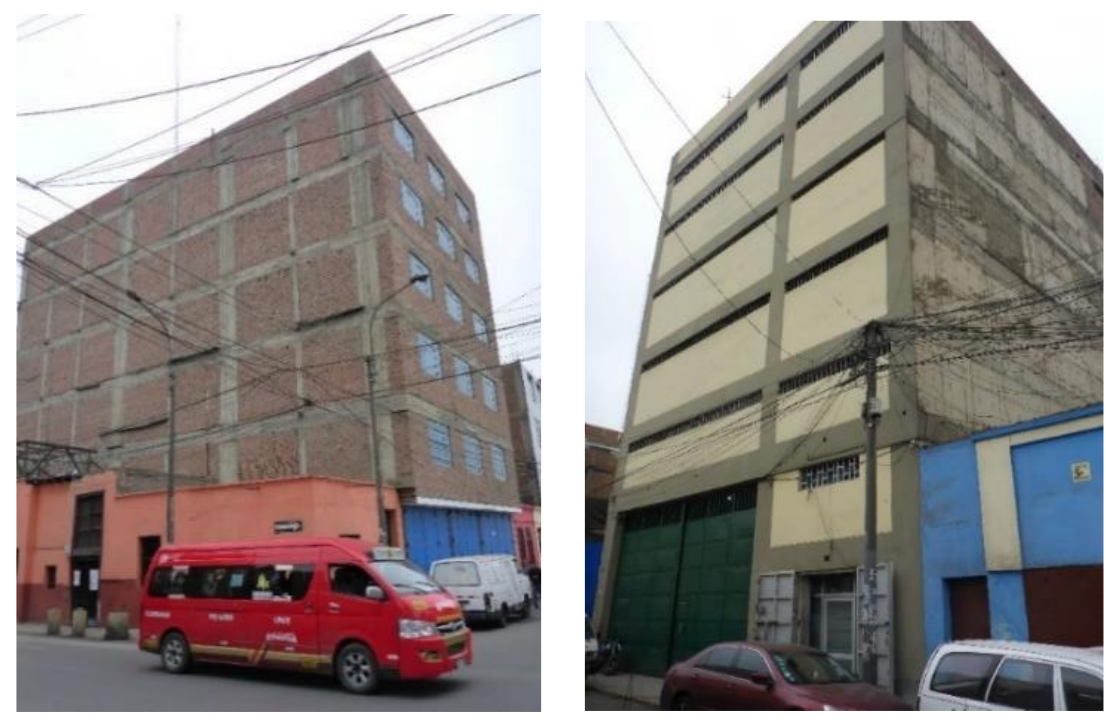
En Jirón Cusco el atractivo del suelo para la inversión en actividades comerciales resulta en presión sobre los residentes de las casonas: "la posibilidad de ser desalojados forma parte de la cotidianeidad y, pese a que son eventos disruptivos, son normalizados y organizan el tiempo social y las estrategias residenciales" (op.cit., p.53). Así, la inminente posibilidad de ser desalojados de las viviendas responde a futuros usos mixtos o exclusivamente usos comerciales de los predios, ya que se necesita espacios para almacenar mercadería.

Habría que hilar más fino para ver la evolución sociodemográfica en el área de Jirón Cusco y su alrededor, así como las consecuencias de la tendencia a la monofuncionalidad comercial. Podemos percibir, desde el siglo XIX, transformaciones hacia una hegemonía comercial del Jirón Cusco, en detrimento de otros usos, como el residencial.

Jirón Cusco es una calle más difícil de comprender aislada de su entorno, o sea, Mesa redonda y Barrios Altos, área del antiguo centro de Lima que, en el pasado, era periferia urbana. Por su condición periférica, de arquitectura menos monumental, y por la densidad de usos y funciones de las últimas décadas, los cambios de paisaje a lo largo del tiempo fueron intensos, como también no hay tantas fuentes documentales que registre informaciones solamente el Jirón Cusco. Más bien hay fuentes sobre Barrios Altos y aún más de calles que en el pasado era ocupada por la élite colonial, que no es el caso de Mesa Redonda. La historia del Jirón Cusco, asimismo, está íntimamente relacionada con la inmigración china y la dinámica comercial de estos migrantes. Y en los días actuales, por el comercio popular e informal en alta densidad.

\section{CALLE EL SOL - CIUDAD DEL CUSCO}

Seguramente, toda la población cusqueña, como también los turistas que visitan Cusco, pasan por la calle/avenida El Sol, por su ubicación céntrica, por sus múltiples usos y por ser vía de paso del transporte colectivo, privado y de buses turísticos. Más precisamente, ella atraviesa gran parte del centro histórico, se extiende de noroeste a sureste, como podemos ver en la figura 6. Tiene su tramo inicial cerca de Plaza de Armas (noroeste) y termina en la confluencia de las calles Tullumayo y San Martín (sureste).

Al contrario del Jirón Cusco, la Calle El Sol tiene el tramo inicial en la parte monumental del centro histórico y es visitada por distintos agentes sociales y turistas, con usos que mesclan comercio, ocio y servicios. La Calle El Sol es una vía que une partes importantes de la ciudad, como la zona monumental del centro histórico, la Alameda Pachacútec y la Estación de Wanchaq, que recibe diariamente los pasajeros que viajan en buses, desde diversas partes de Perú. 
Figura 6. Calle el Sol - 2019, Localización de la Calle El Sol. Fuente: Open Street Map, Google Earth. Proyecto Cartográfico: Carvalho (2019).

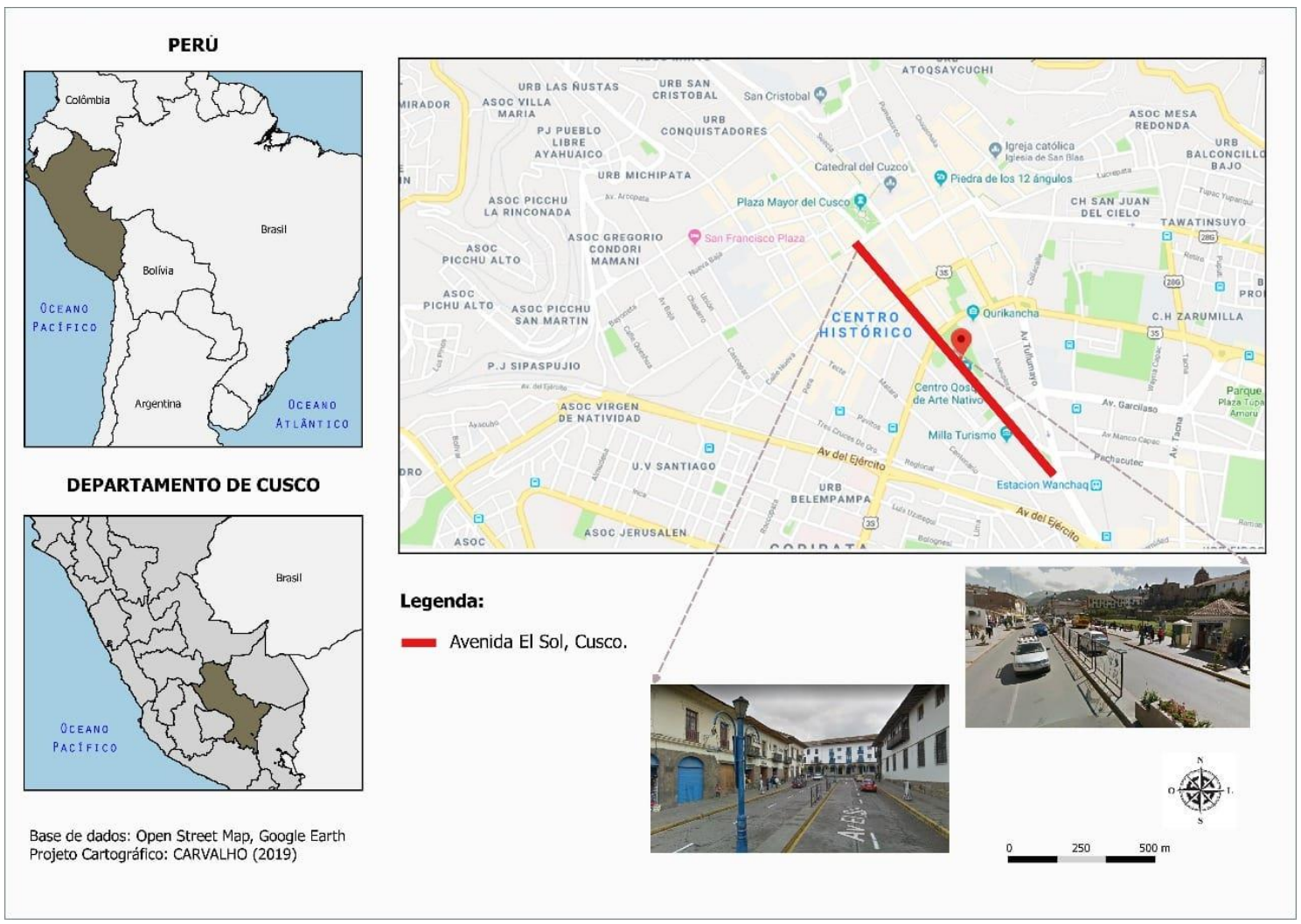

A principios de siglo XX, la ciudad del Cusco lucía como un pueblo de la sierra del Perú, es decir, con los ríos que la atravesaban completamente abiertos, que evidenciaban un rostro inadecuado de la ciudad. El modelo de ciudad colonial se encontraba en crisis, debido a la concentración poblacional paulatina en el centro, la aparición de basura y los desagües abiertos, que ocasionaban problemas de insalubridad desde la segunda mitad del siglo XIX.

Influenciados por el Movimiento Higienista de Europa - que era divulgado en los periódicos locales y que se concretaba en calles de Lima - Cusco pasó por proceso de modernización en la primera mitad del siglo XX, más o menos hasta la década de 1940. Entre las novedades, se discutía la reubicación del cementerio, del matadero, del mercado de abastos, mejorar el recojo de basura y la canalización de ríos y riachuelos. Con la canalización del Río Huatanay o Río Saphy, que transcurría por la vía que estamos estudiando, surgió, con apariencia moderna, la Calle El Sol. Coronado (2016, p. 123) describe:

Una de las principales canalizaciones fue la del río Huatanay, debido a que atravesaba el centro y dividía a la ciudad en dos, el oriente y el poniente. En esta segunda etapa se canalizó desde el puente Rosario hasta la Estación del Ferrocarril. Años más tarde, esta vía tomaría el nombre de avenida El Sol o "avenida de los Incas" y se convertiría en la principal arteria de la ciudad.

Las dos imágenes de la figura 7 muestran la Calle El Sol, respectivamente, antes y después de la canalización del Huatanay. Podemos ver esta calle (imagen a la derecha) con edificaciones transformadas, que 
se volvieron más modernas. Observamos también el desaparecimiento del río, para dar paso a una vía pavimentada. Las nuevas edificaciones también posibilitaron usos más allá del residencial, como el comercial.

Figura 7. Calle el Sol - 1911 e 1939, Calle el Sol. Imagen izquierda: Tramo inicial de la Avenida el Sol, 1908 - 1911; imagen derecha: tramo inicial de la Avenida el Sol, 1939. Fuente: Coronado e Callanaupa, 2017.
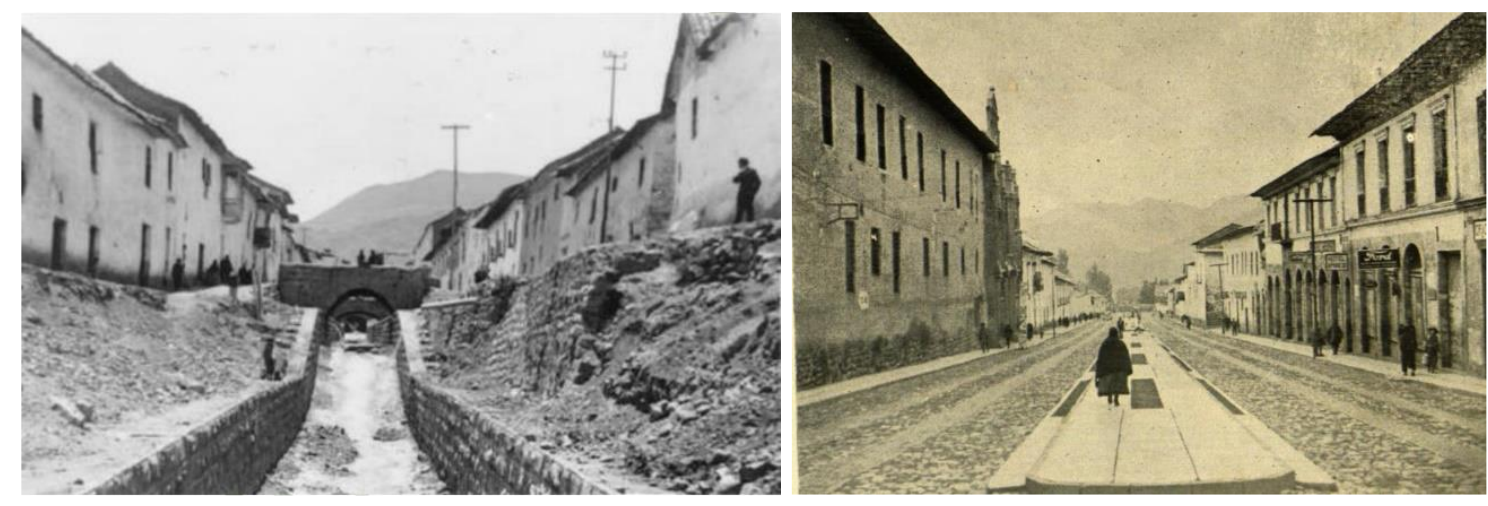

La traza de la Calle El Sol, larga y recta, fue inspirada en el diseño de avenidas modernas, al contrario de gran parte de las calles cusqueñas coloniales, que eran estrechas y apretadas. Así, esta calle reflejó el deseo del poder público y de la sociedad de tener una vía parecida a las que se construía en Lima que, como capital, absorbía el urbanismo burgués de Europa del siglo XIX e inicio del XX.

Al cambiar la forma urbana, se transforma el uso, toda vez que la calle es parte de la morfología urbana, que interfiere en el cotidiano, como explica Maia (2005, p. 8428): “Trata-se, portanto, de um ponto de partida para entendermos a rua na cidade histórica, no que diz respeito à morfologia e ao cotidiano, uma vez que as transformações da morfologia impõem muitas vezes mudanças no vivido". De manera que, al tomar forma de avenida, la Calle El Sol pasó a ser punto de traslado de un sitio a otro de la ciudad, con buena capacidad vehicular, y a tener uso comercial, con un cotidiano más involucrado a la ciudad capitalista.

Coronado (2016) explica que hubo una reestructuración del tejido urbano posteriormente a la modernización, una vez que la nueva red vial, que incluía el centro y la periferia de Cusco, orientó el crecimiento urbano en la segunda mitad del siglo XX. En el centro, se destacaron las calles El Sol y Tullumayo.

Si en la primera mitad del siglo XX tuvo importancia el ordenamiento y planificación de la Calle El Sol, durante la segunda mitad del mismo siglo sucedió lo mismo que en gran parte de las vías de los centros de las ciudades peruanas, que crecieron, tanto debido a la economía formal como al sector informal, denominado de capitalismo popular por Soto (1992).

Así como ocurrió con todo el centro histórico de Cusco, la Calle El Sol tiene ocupación que genera conflicto y competencia por la apropiación de los espacios, por ser preferida por varios agentes sociales y 
económicos. Se trata de un espacio disputado (DUHAU; GIGLIA 2016) con uso y apropiación que presentan conflicto y diversidad Carlos (2001).

En el tramo noroeste, la Calle el Sol se integra al espacio monumental del centro histórico y sigue siendo un eje financiero de los más importantes de Cusco. Compite y a la vez establece relación de complementariedad con otras zonas financieras, como la Avenida de la Cultura y el Centro Comercial Real Plaza, ubicados ambos fuera del centro histórico, en la zona sudeste de Cusco. La Calle El Sol es el eje financiero más antiguo de Cusco y permanece con igual importancia.

Actualmente, es una de las vías más transitadas de Cusco. Ella está ubicada entre dos espacios públicos importantes, como la Plaza de Armas y la Alameda Pachacutec, en el distrito de Wanchac, al sur del distrito de Cusco, como mencionamos anteriormente. A la vez, representa un relevante espacio público, frecuentemente subvertido por actividades privadas, tomado por transeúntes diversos, como turistas, ciudadanos y vendedores ambulantes. La figura 8 permite ver esta calle con personas, destacando una campesina con su hijo, en una tarde lluviosa.

Figura 8. Calle el Sol - 2016, Calle el Sol. Dinámica de fin de tarde, en un día lluvioso. Fuente: trabajo de campo, febrero del 2016. Fotografía: Rita de Cássia Gregório de Andrade.

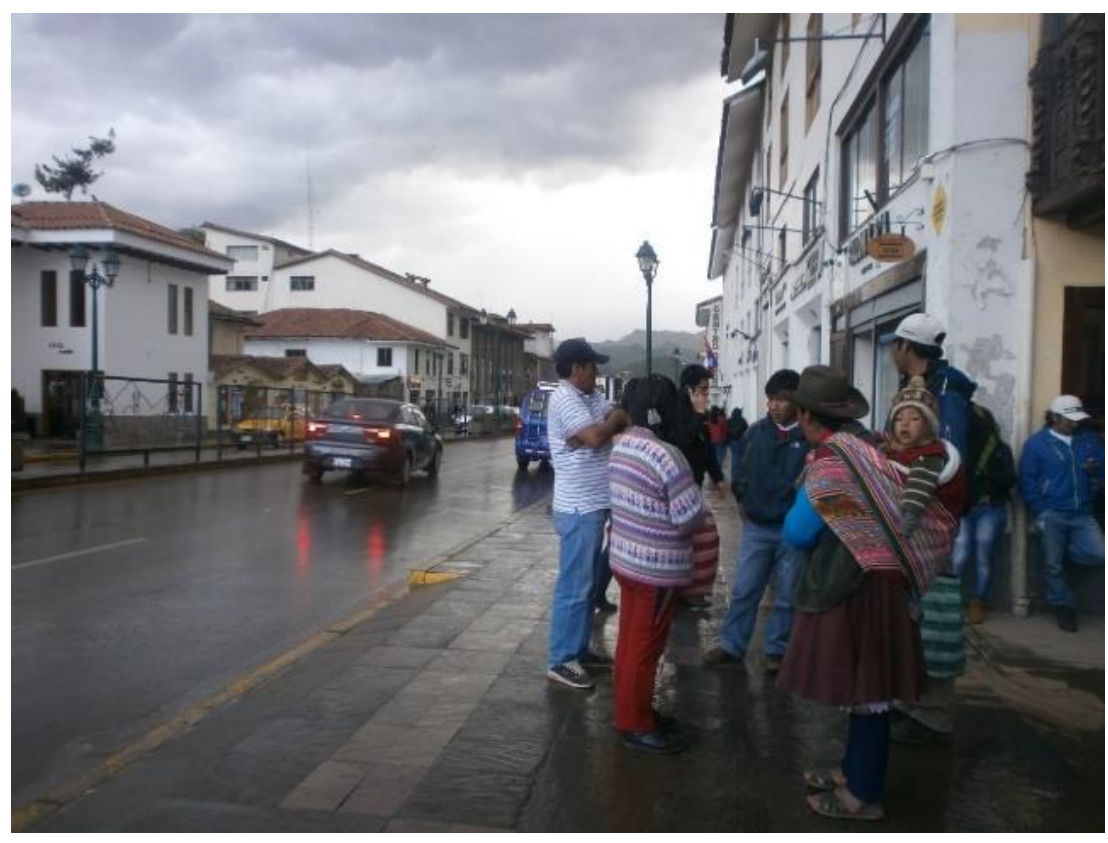

Con respecto al uso del suelo, en primer lugar, posee puntos turísticos importantes, como el Templo del Qoricancha o Del Sol, imbricado al Convento de Santo Domingo. El mural de Juan Bravo Vizcarra también es visitado por los turistas (figura 9). 
Figura 9. Atractivos turísticos de la Calle el Sol - 2016 Templo de Qoricancha y Mural del Vizcarra. Calle El Sol Fuente: trabajo de campo, febrero del 2016. Fotografía: Rita de Cássia Gregório de Andrade.
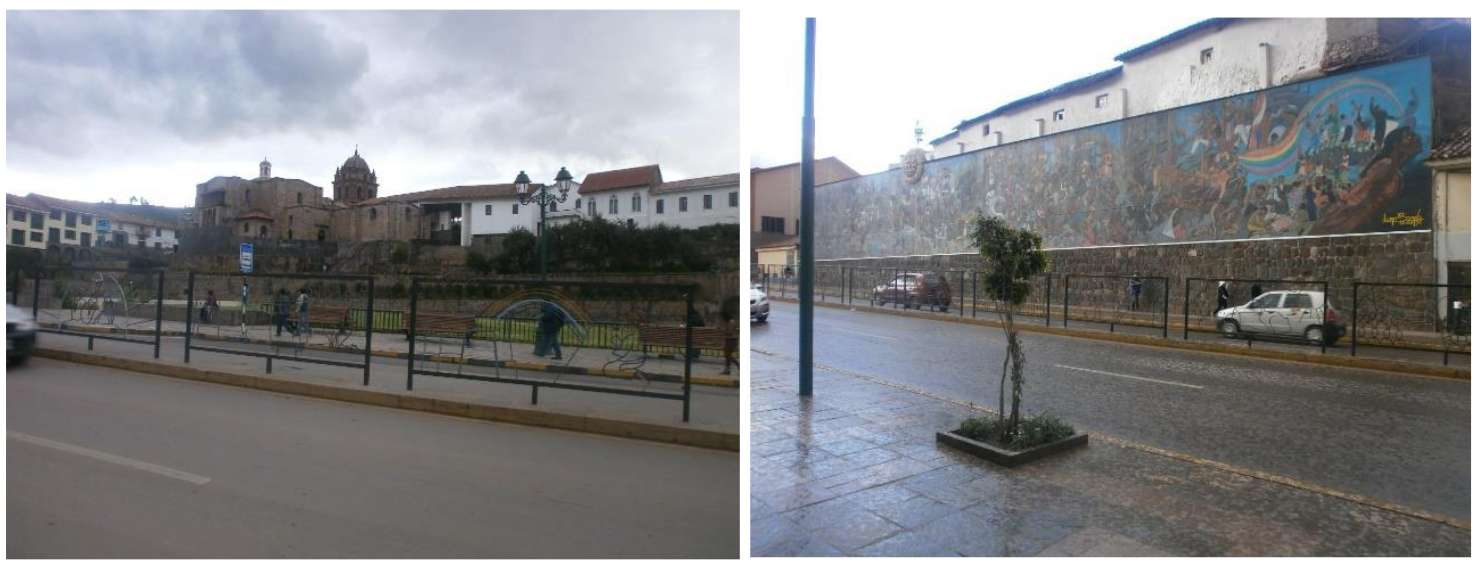

En segundo lugar, alberga el Palacio de Justicia y la Municipalidad Provincial, que funcionan en edificaciones construidas en la primera mitad del siglo XX: "al promediar el siglo XX y entubarse el río Huatanay, construyéndose la avenida Sol, ésa ha pasado a ser otra vía prestigiada, ya que llega a unir la parte baja de la ciudad con la plaza pasando por nuevos hitos, como el palacio de justicia" (VIÑUALES, S/D, p. 11771178).

En la figura 10, podemos ver los predios en los cuales funcionan el Registro Nacional de Identificación de Estado Civil (RENIEC), al lado del Instituto Nacional de Estadística e Informática (INEI) y la Municipalidad del Cusco.

Figura 10. Predios de instituciones importantes en la Calle el Sol - 2015, Predios de RENIEC - a su costado, en el edificio blanco, funciona el INEI y la Municipalidad Provincial del Cusco. Calle El Sol. Fuente: trabajo de campo, febrero del 2015. Fotografía: Rita de Cássia Gregório de Andrade.
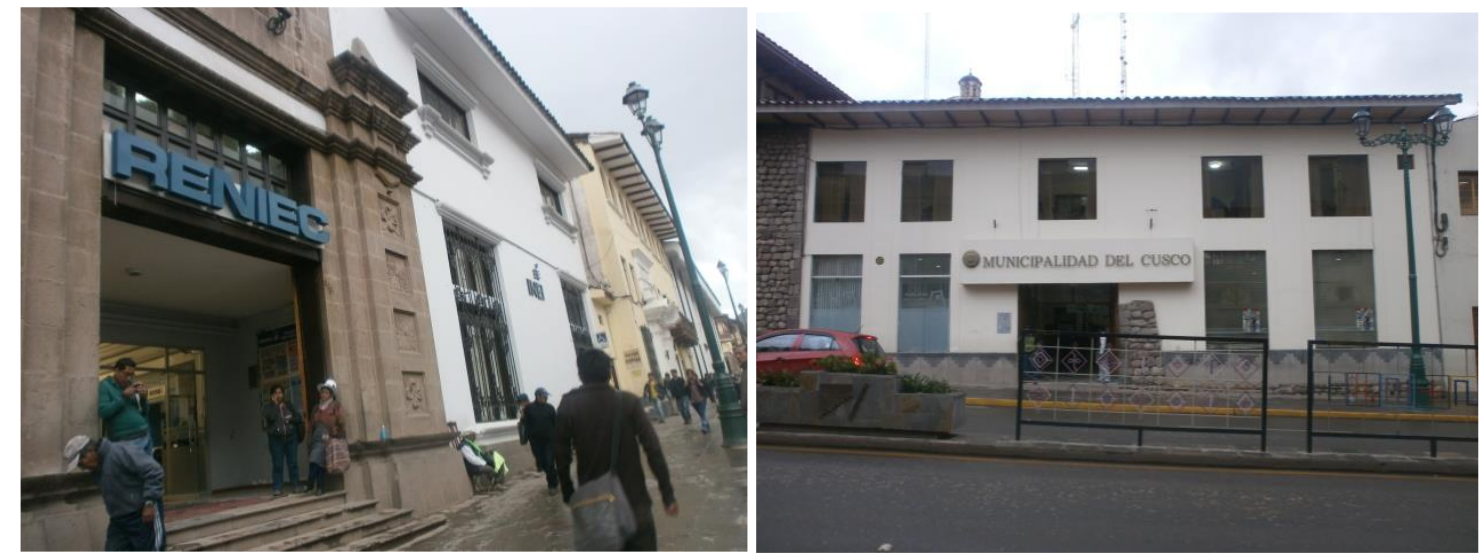
En tercer lugar, en esta calle funcionan los principales bancos, como el Banco de Crédito del Perú, el Banco Continental e Interbank, así como casas de cambio (figura 11). Por ello, en ella el cotidiano está marcado por las transacciones de turistas y de los habitantes, especialmente trabajadores del centro histórico.

Figura 11. Servicios financieros con destaque para atención a los turistas -2019 , Establecimientos de servicios financieros. Calle el Sol. Fuente: trabajo de campo, febrero del 2016. Fotografía: Rita de Cássia Gregório de Andrade.
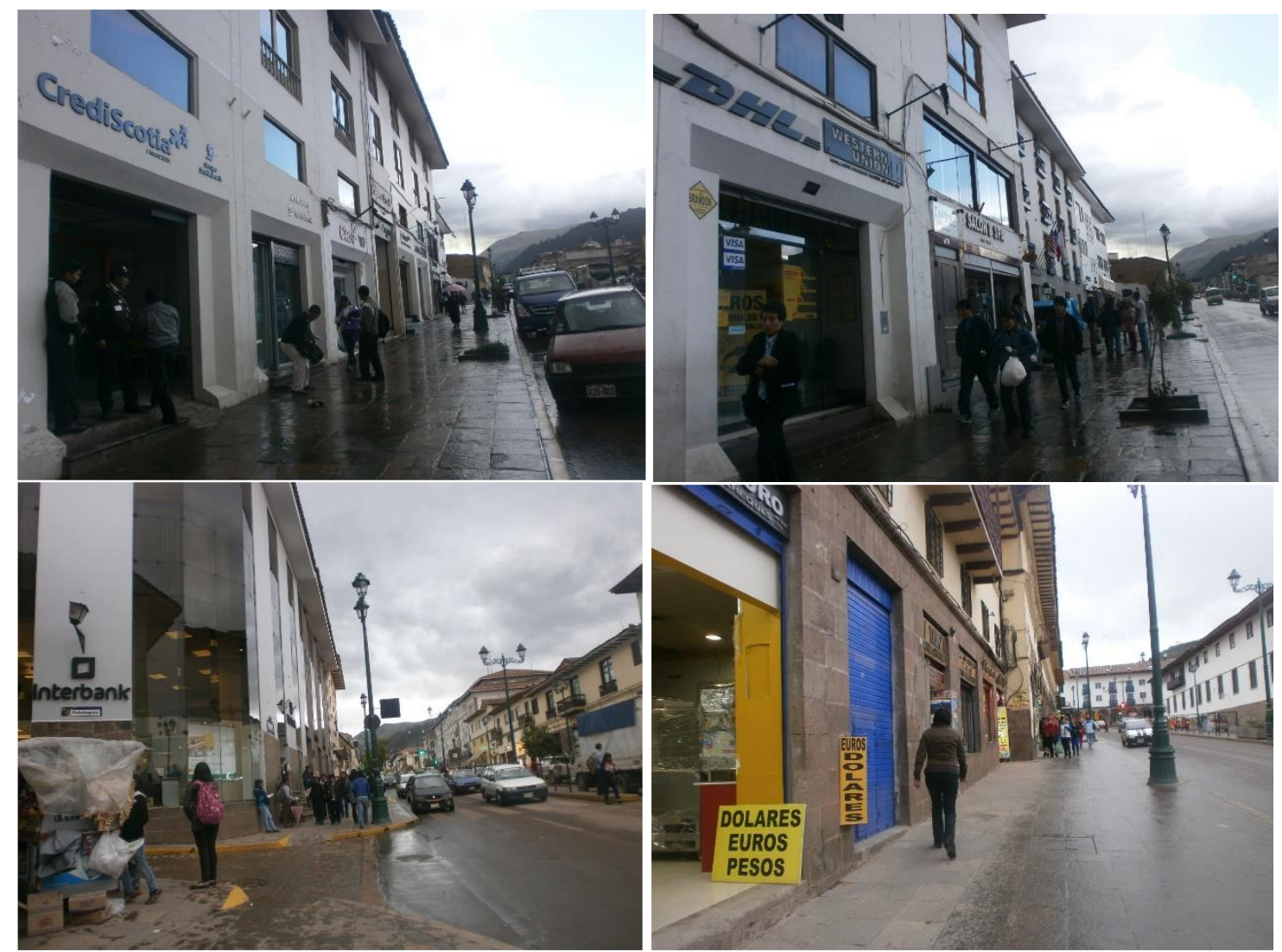

Por último, señalamos que hay fuerte dinámica comercial y de servicios para los turistas, como restaurantes, hoteles, agencias de viajes, mercadillos, galerías comerciales y tiendas especializadas en venta de productos artesanales. En este punto, se asemeja a buena parte de las calles del centro histórico, puesto que, desde la década de 1960, el centro pasa por un proceso de disminución del uso residencial y vocación para comercio y servicios, con el fortalecimiento del turismo internacional. De hecho, el cotidiano de la Calle El Sol tiene que ver con lo que dice Lefebvre (1999, p. 31), es decir, "a rua converteu-se em rede organizada pelo/para o consumo".

Los turistas también acuden a las tiendas artesanales presentes en esta calle, principalmente en su tramo final, cerca del cruce con la Avenida Tullumayo, próximo de la Alameda Pachacútec. Uno de esos centros de venta de artesanías mostramos en la figura 12 , junto con un establecimiento de comida. 
Figura 12. Comercio de artesanía y servicios de comida - 2016, Mercado Artesanal de Productores Inti Padarex y La Tardienda. Calle el Sol. Fuente: trabajo de campo, febrero de 2016. Fotografía: Rita de Cássia Gregório de Andrade.
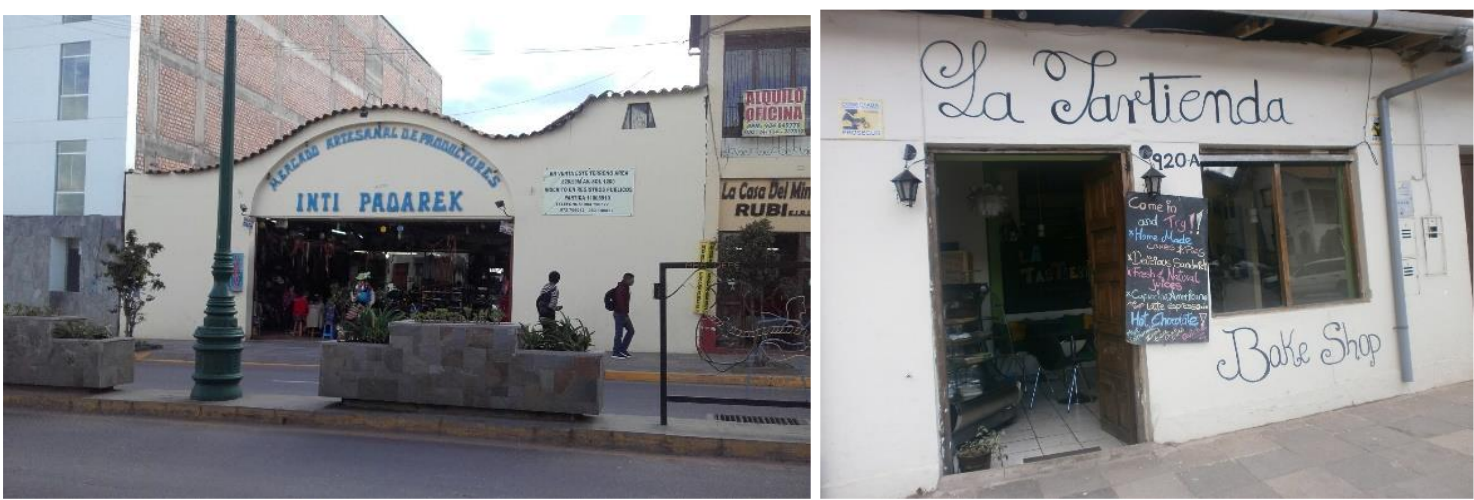

Debido a la buena accesibilidad, es una calle concurrida por turistas, ciudadanos, trabajadores del comercio ambulatorio, comerciantes, funcionarios públicos, buses, taxis, carros y carretillas ambulantes. La calle es un lugar de flujos de capital, ciertamente, pero también es un lugar de permanencia. El comercio ambulatorio, tanto en el Jirón Cusco como de la Avenida El Sol, señala a los peatones que la calle es un fin en sí mismo (CABRAL, 2005).

En todo el tramo, podemos encontrar vendedores ambulantes, con sus carretillas, módulos instalados en alguna esquina, o con productos ubicados en la acera, como podemos apreciar dos ejemplos en la figura 13.

Figura 13. Comercio ambulatorio en Calle el Sol - 2016, venta en carrito y comercio ambulante. Calle el Sol. Fuente: trabajo de campo, febrero de 2016. Fotografía: Rita de Cássia Gregório de Andrade.
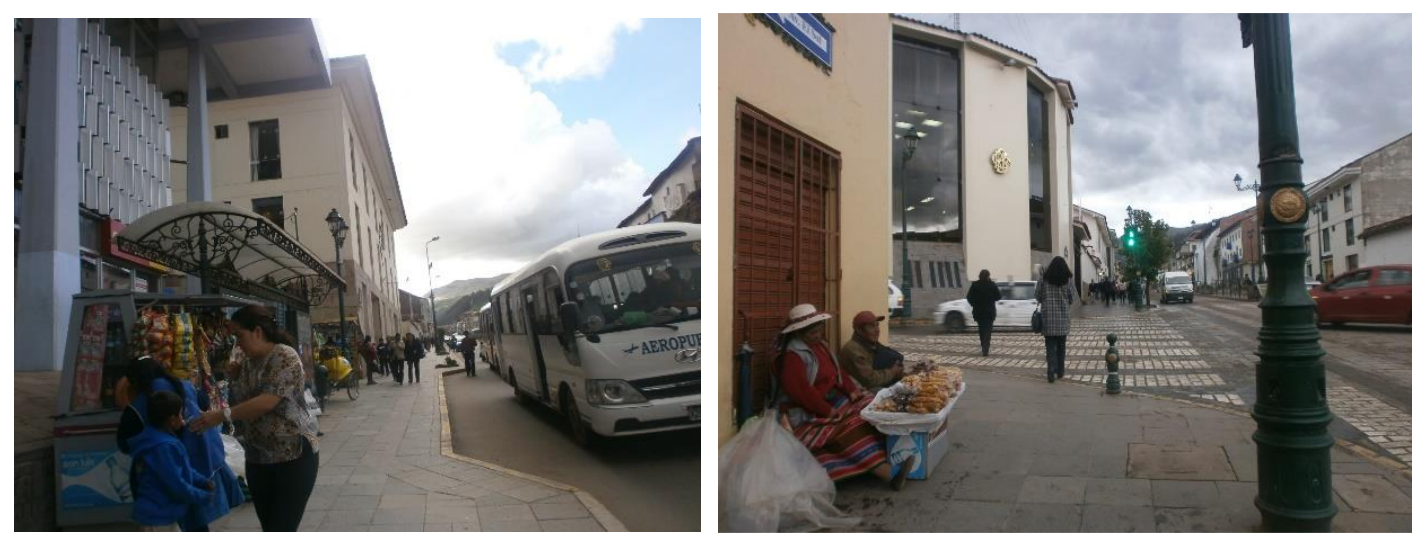

En resumen, la Calle el Sol es un eje financiero, comercial, de servicios y de sedes de instituciones públicas y privadas. Por lo tanto, gran parte del flujo diario de personas de toda la ciudad es debido a las 
instituciones importantes del poder público, que están ubicadas ahí, y el flujo al comercio y a actividades financieras ocurre principalmente por turistas y trabajadores del centro. Los habitantes de Cusco pueden elegir varios locales para esto, como la Avenida de la Cultura o el Centro Comercial Real Plaza, porque suelen desplazar por toda la ciudad, al contrario de los turistas que se limitan mayormente al centro histórico.

Vemos la importancia del estudio de esta calle, así como del Jirón Cusco, para aproximarnos a la historia de distintas ciudades. Asimismo, aunque las ciudades posean sus singularidades, percibimos que hay puntos comunes entre calles de Latinoamérica y, incluso, de otros continentes. El principal punto en común en ciudades del Occidente es como fueron afectadas por los ideales de modernidad europea y luego, por los conflictos y desigualdades sociales, que se intensificaron durante los siglos XX y XXI, especialmente en Latinoamérica. Cusco, como ciudad intermedia de fuerte presencia de cultura andina, se vio afectada por la modernidad y, más recientemente, por la economía terciaria del capitalismo terciario y el turismo. La Calle El Sol es parte de estos procesos, que involucran patrimonio cultural, modernidad, turismo, comercio, servicios financieros y consumo.

\section{CONCLUSIONES}

El carácter híbrido de las calles estudiadas se manifiesta por los ritmos diferenciados, en tanto que pueden ser lugares de paso, de visita turística, de reunión y encuentro, pero también de trabajo.

Ambas calles pasaron por intensas transformaciones, que cambiaron su forma y uso. Jirón Cusco fue una calle residencial y comercial, de influencia del comercio chino en el pasado, y que, a lo largo del siglo XX, como parte del centro antiguo de Lima, paso por procesos de intensa ocupación, precariedad de varias edificaciones, cambios inmobiliarios y conflictos de diversos agentes sociales por su apropiación. En ella hay, hoy, predominancia del comercio en los predios y en la vía pública, con destaque para el sector informal.

La Calle El Sol, que cobra mayor importancia en el centro histórico de Cusco, igualmente, pasó por varias transformaciones. De calle que tenía un río en su transcurso, con uso residencial, a una avenida moderna y, actualmente, de uso financiero, comercial y turístico. Vemos, a través de estas calles, una hegemonía capitalista del uso comercial, para Jirón Cusco, y de comercio imbricado a servicios y financias, para Calle El Sol, dos vías ubicadas en distintos contextos espaciales de dos centros históricos.

Ambas calles contienen elementos de la economía capitalista, periférica mundialmente, donde las actividades terciarias, vinculadas al comercio y otros servicios, estructuran la ciudad. Las diferencias son notables entre la Calle El Sol y el Jirón Cusco, pues en este último la intensidad del comercio tiene carácter monofucional a esta parte del centro histórico de Lima. Esto se observa en Mesa Redonda, donde el consumo es el eje articulador del Jirón Cusco. Se trata de un tipo de comercio que, dada su intensidad y difícil regulación, 
pone en riesgo a los habitantes y a los trabajadores de este sector. El carácter público de este espacio es mezclado con actividades privadas o, en todo caso, la calle se configura como espacio de ampliación de las actividades lucrativas, mezclada con las de sobrevivencia.

En ambas calles, sin embargo, observamos conflicto y competencia por la apropiación del espacio, por lo que resulta necesario comprender a mayor profundidad las presiones que se están generando, así como qué impactos tienen para los residentes. Sobre este último punto, se observa que desde 1960, el centro histórico del Cusco deja progresivamente de ser un espacio residencial para volcarse a diversas actividades económicas, a demanda del turismo internacional.

Estas calles no se agotan en sí mismas; para obtener un panorama más acabado es fundamental realizar un análisis multiescalar que tome en consideración las manifestaciones locales de la economía capitalista. Sin embargo, es fundamental sumar al análisis procesos cuya aparición se manifiesta en la cotidianeidad de los habitantes urbanos. En este sentido, consideramos que los elementos presentados ayudan a comprender algunos procesos en marcha en dos ciudades peruanas.

Finalmente, afirmamos que la exploración y descripción de dos calles de ciudades peruanas demuestran la importancia de los estudios de caso, pues, confirmamos a la vez tendencias universales (u occidentales) que impactan el proceso de urbanizaron latinoamericano y tendencias particulares de ciudades con centros históricos. En lo que se refiere al primer punto, vemos la absorción de la modernidad por parte de las élites, en un primer momento, y el fenómeno de escape del uso residencial de los centros antiguos de la ciudad, que se llenan de actividades comerciales y de servicios, con vías públicas tomadas por vehículos y comercio ambulante, en un segundo momento. En lo que se refiere a elementos particulares, vemos la intensidad del turismo en Cuzco e en su centro histórico, que se refleja en la Calle El Sol, y la influencia profunda del comercio informal en Lima, como capital nacional, de un país de red urbana concentrada, que se manifiesta con mayor intensidad en el Jirón Cusco, como calle ubicada en la periferia del centro histórico, fuera de la zona monumental.

Parafraseando a Lefebvre (1999), se trata de espacios para el consumo a la vez que se consume el espacio. Por eso, el conocimiento generado sobre ambas calles, su forma y uso, pasado y presente, inspira a proposiciones que valoricen el comercio de los ciudadanos habitantes de Lima y Cuzco, iniciativas de valorización de la sociabilidad, seguridad y conservación del patrimonio y, quizás, diversificar sus funciones, con rescate del uso residencial. De manera que, sea un espacio no solo de consumo, como de uso para sociabilidad. 


\section{REFERÊNCIAS}

BORJA, Jordi. Revolución urbana y derechos ciudadanos: claves para interpretar las contradicciones de la ciudad actual. Tesis doctoral: Universidad de Barcelona, 2012.

BRESCIANI, Maria Stella Martins. Nas ruas, o caminho da cidade. Cadernos de História de São Paulo: A cidade e a rua. São Paulo, Museu Paulista da Universidade de São Paulo, n.2, p. 26-38, janeiro-dezembro 1992.

CARLOS, A. F. A. Espaço e Tempo na Metrópole. São Paulo: Contexto, 2001.

CAPEL, H. La morfologia de las ciudades. Barcelona: Ediciciones del Serbal, 2002.

CAPEL, Horacio. A modo de introducción: Los problemas de las ciudades. Urbs, civitas y polis. Colección Mediterráno Económico, (3), pp. 9-22, 2003.

CHICOMA, Pierina. Incendio en Mesa Redonda: 10 fotos que dejó la tragedia del 2001, El Comercio, 2017.

CORONADO, Jéssica Esquivel. La modernidad en el Cusco: la necesidad de contar con un plan director y un reglamento de construcciones durante la primera mitad del siglo XX. In: Crónicas urbanas. Análisis y perspectivas urbano-regionales. Centro de Educación y Comunicación “Guaman Poma de Ayala”, ano XVIII, n. 19, 2016.

CORONADO ESQUIVEL, Jessica y APAZA CALLAÑAUPA, Roel. La modernización de la ciudad y su salubridad: la canalización del Cusco a principios del siglo XX. Summa Humanitatis, vol. 9, número 1, pp. $110-168,2017$.

DAMMERT, Guardia, Manuel. (2018). Precariedad urbana, desalojos y vivienda en el Centro histórico de Lima. Revista Invi, 35 (94), p.51-76.

DELGADO, Manuel. El animal público, Barcelona: Anagrama, 1999.

DUHAU, Emilio; GIGLIA, Angela. Metrópoli, espacio público y consumo. México: Fondo de Cultura Económica, 2016.

FERNÁNDEZ-MALDONADO, Ana María. Las barriadas de Lima como estímulo a la reflexión urbana sobre la vivienda. Revisitando a Turner y De Soto. Wasi, 2(3), 7-24, 2015.

HU, Evelyn. Chinos comerciantes en el Perú: Breve y preliminar bosquejo histórico (1869-1924). In: Morimoto, Amelia y Luciano, José Carlos (ed.). Primer seminario sobre poblaciones inmigrantes. Actas. Lima: Concejo Nacional de Ciencia y Tecnología, 1987.

MAIA, Doralice Sátyro. A morfologia urbana no movimento da modernidade. Anais do X Encontro de Geógrafos da América Latina 20 a 26 de março de 2005 - Universidade de São Paulo.

Ruas, casas e sobrados na Cidade Histórica: entre ruínas e embelezamentos, os antigos e novos usos. X Coloquio de Internacional de Geocrítica, Barcelona, 26 - 30 de Mayo de 2008, Universidad de Barcelona.

http://www.ub.edu/geocrit/-xcol/150.htm Consulta en 22 de julio de 2019.

MEYER, Regina Maria Prosperi. O papel da rua na urbanização paulistana. Cadernos de História de São Paulo: A cidade e a rua. São Paulo: Museu Paulista da Universidade de São Paulo, n.2, p. 13-25, janeiro-dezembro 1992.

MC KEOWN, Adam. Chinese migrant networks and cultural change. Peru, Chicago, Hawaii, 1900-1936. Chicago: Chicago University Press, 2001.

LEFEBVRE, Henri. A Revolução Urbana. Belo Horizonte: UFMG, 1999.

RAMÍREZ-CORZO, Daniel. Epidermis. Documental sobre el incendio de Mesa Redonda y su memoria. 2017.

SATO, José. El desastre sísmico que podemos evitar. Mirando al Perú. Lima: Oxfam, pp.92-99, 2012. 